\title{
Frequency of Ovarian Tumors According to WHO Histological Classification and Their Association to Age at Diagnosis
}

\author{
Muhammad Arif Khan, ${ }^{1}$ Saira Afzal, ${ }^{2}$ Hassan Saeed, ${ }^{3}$ Hnia Usman, ${ }^{4}$ Rooqash Ali, ${ }^{5}$ Manaquibb Zain Ali \\ Shaheer Khan, ${ }^{6}$ Aqsa Mumtaz, ${ }^{7}$ Nimra Ramazan, ${ }^{8}$ Alina Fatima, Jawad Haider, ${ }^{10}$ Ahmad Latif, ${ }^{11}$ Anum \\ Nawaz $^{12}$
}

\begin{abstract}
Ovarian tumors, or ovarian neoplasms, are benign or malignant tumors arising from the ovaries. They may arise from any of the three components of ovary i.e. surface epithelium, germ cells and the stroma of the ovary including sex cords. Tumors in the ovary can also be secondary or metastatic tumors.

Objective: To determine the frequency of Ovarian Tumors according to WHO Histological classification and their relation to age at diagnosis in almost one year.
\end{abstract}

Methods: A cross-sectional study was carried out, that included all the consecutive cases of ovarian neoplasms diagnosed at the Pathology department of a public sector university in Lahore from 1 January 2015 to 13 February 2016.

Results: In 95 female patients diagnosed with ovarian tumors, the mean age was found to be $29.58 \pm$

1 Assistant Professor of Nutrition Sciences

The University of Lahore

2 Chairperson, Dept of Community Medicine

King Edward Medical University, Lahore

3-12 MBBS Student, KEMU

Date of Submission: 23-08-2016

Date of $1^{\text {st }}$ Revision Received: 14-02-2017

Date of Acceptance for Publication: 10-05-2017

Conflict of Interest: None

Funding Source: None

\section{Contribution}

All Authors have contributed in Study Design, Data Collection, Data Analysis, Data Interpretation, Manuscript Writing and Approval.
11.493 with a range of 3-65 years. Tumors were most common between the ages of 15 to 30 years. The highest rates of malignancy were in the 0-15 and 45-60 age groups (Figure 1). About $78.9 \%$ of the tumors (75/95) were benign, $1.1 \%$ (1/95) were borderline and $20 \%$ (19/95) were malignant (Figure 3), 72.6\% (69/95) were epithelial tumors, $23.2 \%$ (22/95) were germ cell and $4.2 \%$ (4/95) were sex cord stromal tumors (Figure 4). Among the 95 cases, serous tumors were the most common $(49.5 \%)$, followed by mucinous $(16.8 \%)$ and teratomas $(15.8 \%)$.

Conclusion: According to our study, ovarian tumors were common between the age of 15 to 29 years. Benign neoplastic lesions were more common than malignant neoplastic lesions. The frequency of malignant and benign ovarian neoplasms found in our research differed from other studies conducted in Pakistan. There is a significant association of ovarian tumors in age less than 30 year as compared to older age groups $(\mathrm{P}<0.001)$.

Key Words: Benign, Malignant, Neoplastic, Nonneoplastic, Ovarian tumors, Serous Cystadenoma, Serous Cystadenocarcinoma.

\section{Introduction}

Tumor is defined as an abnormal mass of tissue, the growth of which exceeds and is uncoordinated with that of normal tissue and persists in the same excessive manner after cessation of stimuli which evoked the change. ${ }^{1}$ Ovarian tumors are tumors arising from any of the three components of ovary i.e. surface epithelium, germ cells and the stroma of the ovary including sex cords; these can also be secondary or metastatic tumors of ovary. ${ }^{2}$ A tumor is said to be benign when 
its gross and microscopic appearances are considered relatively innocent, implying that it will remain localized, will not spread to other sites, is amenable to local surgical removal. ${ }^{1}$ Malignant tumors can invade and destroy adjacent structures and spread to distant sites to cause death. ${ }^{1}$

Various researches have been carried out to determine the prevalence of histological ovarian tumors in specific age groups. Jha $\mathrm{R}^{4}$ showed that $83.9 \%$ of the ovarian tumors were benign and $16.1 \%$ were malignant, with surface epithelial tumors being most common followed by germ cell tumors. Mondal $\mathrm{SK}^{5}$ reported that most of the benign tumors occurred between 20 and 40 years of age, while the malignant lesions were most frequent between 41 and 50 years of age.Quirk $\mathrm{JT}^{6}$ concluded that epithelial tumors were the most common followed by germ cell tumors, sex cord-stromal tumors, and other miscellaneous ovarian tumors. A number of studies have been done in India as well. Modi ${ }^{7}$ reported that benign neoplasms were most commonly seen in 3rd to 5th decade, whereas malignant neoplasms were commonly seen in the 5th decade. Makwana ${ }^{8}$ and Sharma $I^{9}$ showed that surface epithelial tumor was the most common tumor according to the histogenesis. Researches have also been conducted in Nepal. In Maharjan's study, ${ }^{10}$ surface epithelial tumors were more frequently observed above 30 years of age, germ cell tumors were more common between 20 to 30 years of age and sex cord tumors were only present in the $41-60$ the age group. Another study done in Nepal by Swamy GG $^{11}$ reported that about $2 / 3 \mathrm{rd}$ of all benign neoplasms were seen in patients between 20 to 40 years age, whereas $2 / 3 \mathrm{rd}$ of all malignant neoplasms were seen after the age of 40 yrs. According to Abdullah LS, ${ }^{12}$ surface epithelial tumors constituted the most common ovarian neoplasm followed by germ cell tumors, sex cord stromal tumors and metastatic tumors. Some studies have also been conducted in Pakistan. Ahmad $\mathrm{Z}^{13}$ showed that the most common benign tumors were benign cystic teratoma, serous cystadenoma, mucinous cystadenoma and serouscystadenofibroma. The most common malignant tumors were serous cystadenocarcinoma and mucinous cystadenocarcinoma. Yasmin $\mathrm{S}^{14}$ and Khan $\mathrm{MM}^{15}$ both reported that the most common histologycal patterns observed in the study were epithelial tumors. Another study conducted by Saeed $\mathrm{M}^{3}$ showed that all the ovarian tumors found in the younger age group of $10-16$ years were malignant.

Since the environmental, genetic and cultural factors in Lahore are different from other areas; our study aimed to specifically determine the frequency of various histological types of ovarian tumors in patients of different age groups that came to a tertiary care hospital in Lahore, Pakistan. This research elucidates the epidemiology of various ovarian tumors with respect to age which will aid clinicians in carrying out targeted empirical management of ovarian tumors. It will also help spread awareness in the public about the disease especially about the age groups in which ovarian carcinomas are common. It will also help devising screening programs by providing the age groups which need to be targeted.

\section{Methods}

A cross-sectional study was carried out foranalyzing the reports of all the female patients who were referred to the Pathology department of a public sector university in Lahore from January 2015 to February 2016 and were diagnosed with ovarian lesions by histopathology. The ethical permission to carry out our study was granted by the Intuitional Review Board. Permission to carry out our study was also obtained from the head of the concerned Departments. We used purposive sampling to retrieve the histopathology reports from the concerned Departments in database and included all reports of ovarian neoplasms from $1 / 1 / 2015$ to $13 / 2 / 2016$ irrespective of the surgical procedure by which tumor was removed. We found 95 reports of ovarian neoplasms. Patients with non-neoplastic ovarian lesions and functional cysts were not included. Reports which were incomplete were excluded. Reports that were not authenticated or were not duly signed by a pathologist of the department were also excluded.

The histological classification of ovarian tumors was done according to the WHO classification of ovarian tumors. The data was collected using our data collection tool. The data we acquired was then statistically analyzed using SPSS 16 and the results were then compiled.

\section{Results}

Histopathology reports of the pathology department from $1 / 01 / 2015$ to $13 / 2 / 2016$ were analyzed. There were 95 reports of ovarian tumors. The mean age was 29.58 years \pm 11.493 . The range was $3-65$ years. The age distribution was as follows: 


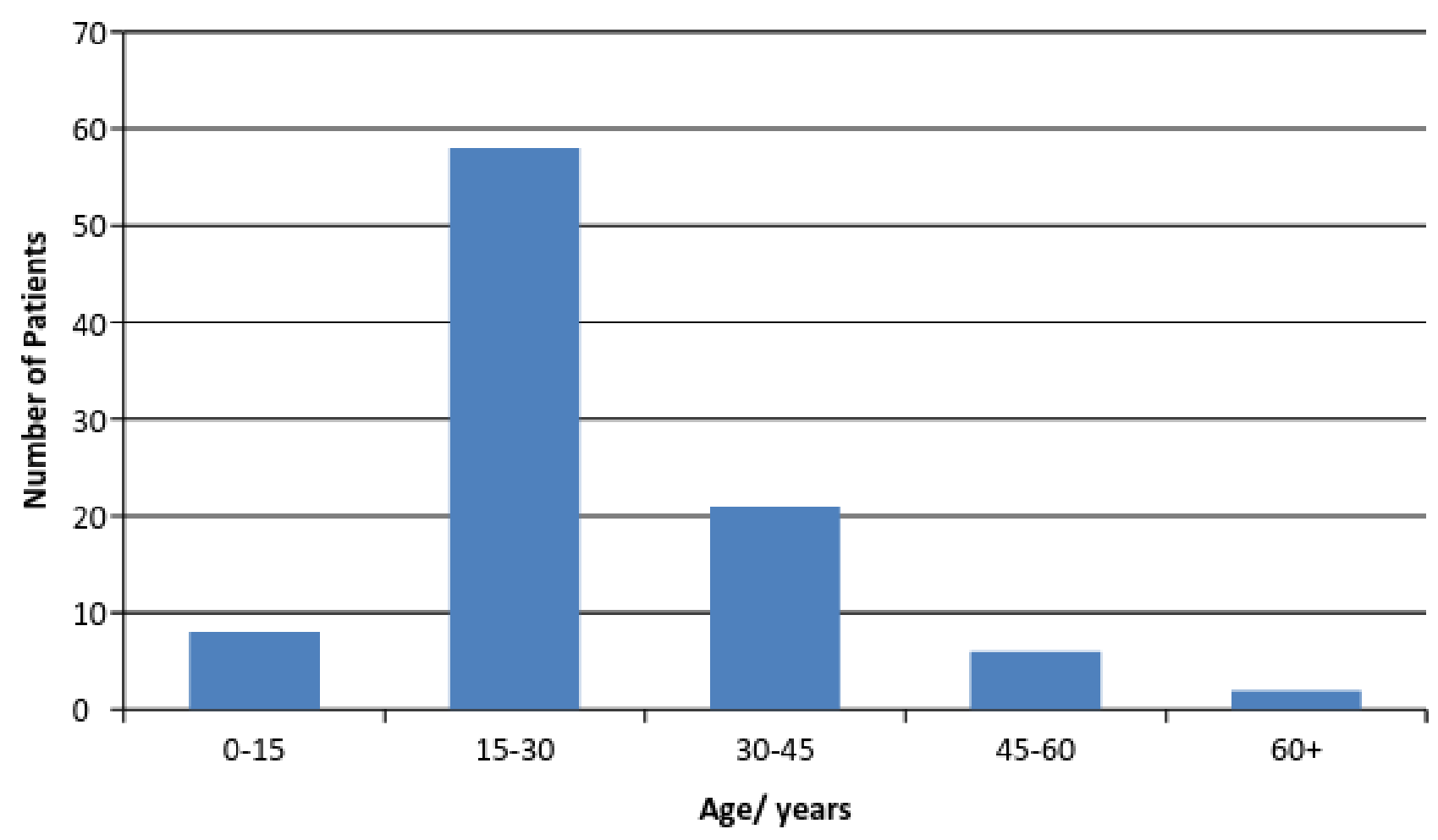

Figure 1: Distribution of Ovarian Tumors in Different Age Groups.

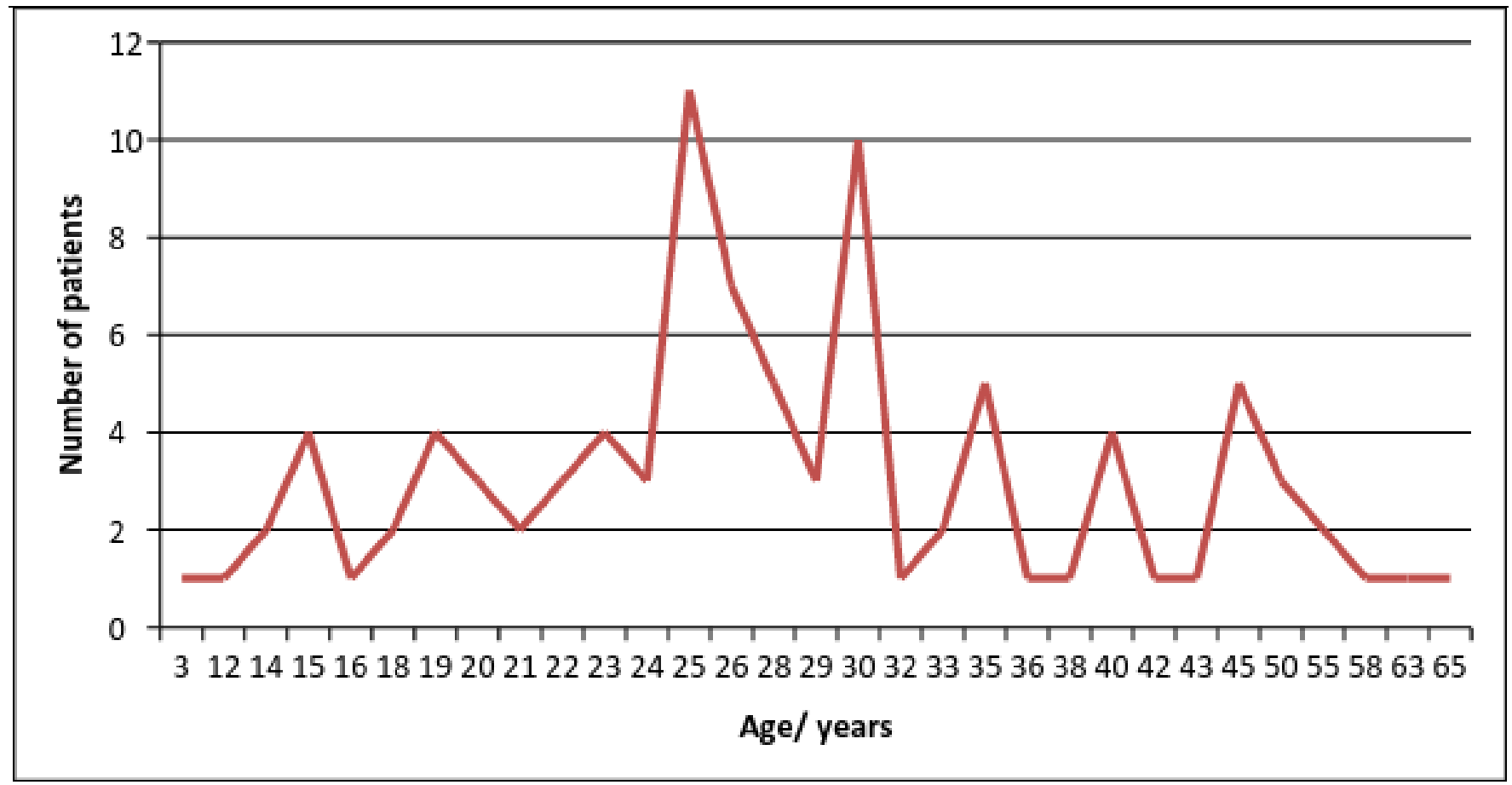

Figure 2: Frequency of Ovarian Tumors with Age. 

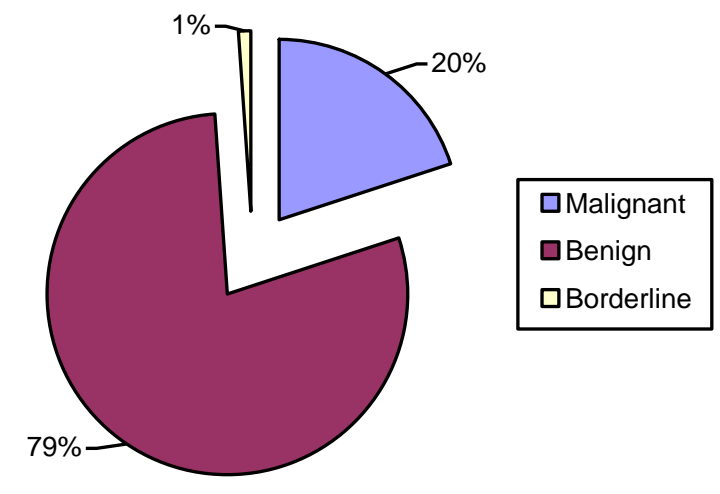

Fig. 3: Pie Chart showing Distribution of Tumors According to Malignant Potential.

In our research $78.9 \%(75 / 95)$ of the tumors studied were benign, $1.1 \%(1 / 95)$ were borderline and $20 \%(19 / 95)$ were malignant (Figure 3). $72.6 \%$ (69/95) were epithelial tumors, $23.2 \%(22 / 95)$ were germ cell and $4.2 \%(4 / 95)$ were sex cord stromal tumors (Figure 4). No metastatic or secondary lesions were found. Among the 95 cases, serous tumors were the most common (49.5\%), followed by mucinous $(16.8 \%)$, teratoma $(15.8 \%)$, dysgerminoma (4.2\%), mixed epithelial tumor (3.2\%), endometroid (2.1\%),

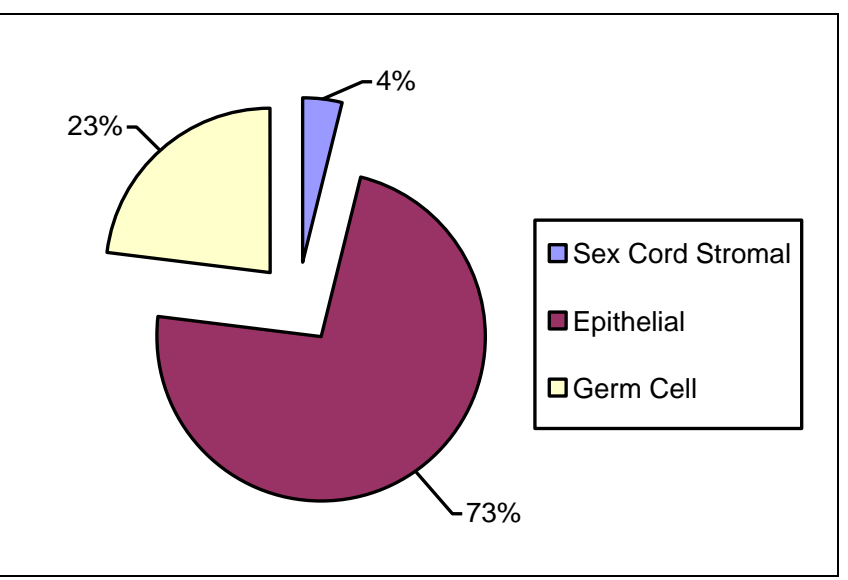

Fig. 4: Pie Chart showing Distribution of Tumors According to Cell of Origin.

granulosa stromal cell tumors $(2.1 \%)$, mixed forms of germ cell tumors $(2.1 \%)$, clear cell $(1.1 \%)$, endodermal sinus tumor $(1.1 \%)$, mixed sex cord tumors $(1.1 \%)$ and fibromas $(1.1 \%)$ (Figure 5).

In the age group $0-14$ years, out of 8 cases, $50 \%$ (4/8) cases were malignant. While in the $15-29,30-$ $44,45-60$ and $60+$ age groups $13.79 \%$ (8/58), $19 \%$ (4/21), 50\% (3/6) and 0\% (0/2) were malignant respectively (Table 3 ).

Germ cell tumors we found to be more common in

Table 1: Distribution of Ovarian Tumors in Different Age Groups Based on Cell of Origin.

\begin{tabular}{|c|c|c|c|c|}
\hline Age Group & Epithelial & Germ Cell & Sex Cord Stromal & Total \\
\hline $0-15$ & $2(25 \%)$ & $6(75 \%)$ & $0(0 \%)$ & 8 \\
\hline $15-30$ & $47(81.03 \%)$ & $10(17.24 \%)$ & $1(1.72 \%)$ & 58 \\
\hline $30-45$ & $15(71.43 \%)$ & $6(28.57 \%)$ & $0(0 \%)$ & 21 \\
\hline $45-60$ & $4(66.67 \%)$ & $0(0 \%)$ & $2(33.33 \%)$ & 6 \\
\hline $60+$ & $1(50 \%)$ & $0(0 \%)$ & $1(50 \%)$ & 2 \\
\hline
\end{tabular}

Table 2: Distribution of Ovarian Tumors in Different Age Groups Based on Malignant Potential.

\begin{tabular}{|c|c|c|c|c|}
\hline Age Group & Benign & Borderline & Malignant & Total \\
\hline $0-15$ & $4(50 \%)$ & $0(0 \%)$ & $4(50 \%)$ & 8 \\
\hline $15-30$ & $49(84.48 \%)$ & $1(1.72 \%)$ & $8(13.79 \%)$ & 58 \\
\hline $30-45$ & $17(80.95 \%)$ & $0(0 \%)$ & $4(19.05 \%)$ & 21 \\
\hline $45-60$ & $3(50 \%)$ & $0(0 \%)$ & $3(50 \%)$ & 6 \\
\hline $60+$ & $2(100 \%)$ & $0(0 \%)$ & $0(0 \%)$ & 2 \\
\hline
\end{tabular}




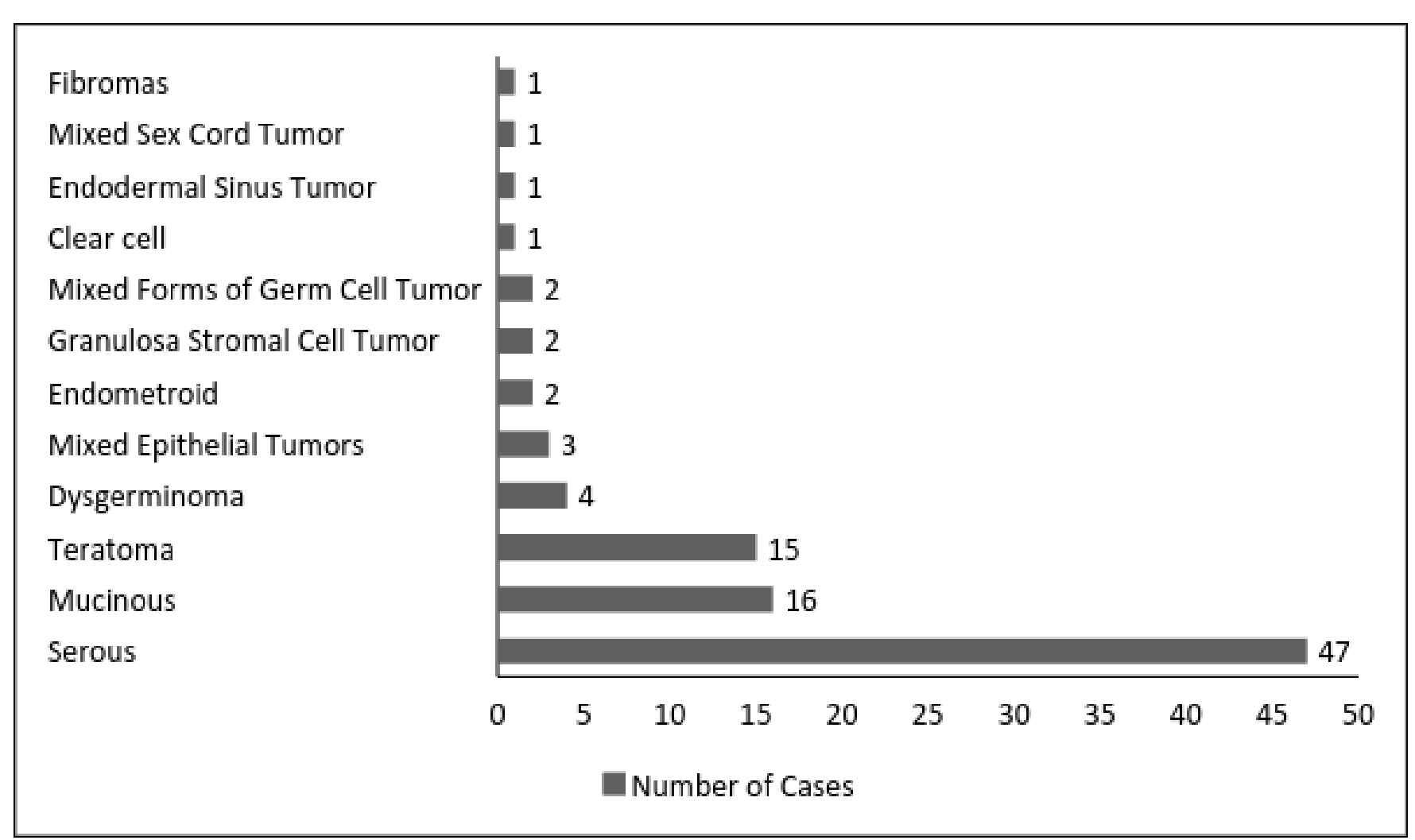

Figure 5: Distribution of Ovarian Tumors in Subclasses According to WHO Histological Classification.

Table 3: Distribution of Histological Subtypes of Ovarian Tumors in Different Age Groups Based on WHO Histological Classification.

\begin{tabular}{|l|c|c|c|c|c|c|}
\hline Histological Type & 0-14 Years & 15-29 Years & 30-44 Years & 45-60 Years & 60+ Years & Total \\
\hline Serous & 1 & 34 & 9 & 2 & 1 & 47 \\
\hline Mucinous & 1 & 10 & 4 & 1 & 0 & 16 \\
\hline Endometroid & 0 & 1 & 1 & 0 & 0 & 2 \\
\hline Clear Cell & 0 & 0 & 1 & 0 & 0 & 1 \\
\hline Mixed Epithelial Tumor & 0 & 2 & 0 & 1 & 0 & 3 \\
\hline Granulosa Stromal Cell Tumor & 0 & 0 & 0 & 2 & 0 & 2 \\
\hline Dysgerminoma & 1 & 3 & 0 & 0 & 0 & 4 \\
\hline Endodermal Sinus Tumor & 1 & 0 & 0 & 0 & 0 & 1 \\
\hline Teratoma & 2 & 7 & 6 & 0 & 0 & 15 \\
\hline Mixed forms off Germ Cell Tumors & 2 & 0 & 0 & 0 & 0 & 2 \\
\hline Mixed Sex cord tumor & 0 & 1 & 0 & 0 & 0 & 1 \\
\hline Fibroma & 0 & 0 & 0 & 0 & 1 & 1 \\
\hline Total & 8 & 58 & 21 & 6 & 2 & 95 \\
\hline
\end{tabular}


Table 4: Distribution of Histological Subtypes of Malignant Ovarian Tumors in Different Age Groups Based on WHO Histological Classification

\begin{tabular}{|c|c|c|c|c|c|c|}
\hline \multicolumn{7}{|c|}{ Distribution of Malignant Tumors in various age groups } \\
\hline Histological Type & $\begin{array}{c}0-14 \\
\text { Years }\end{array}$ & $\begin{array}{l}15-29 \\
\text { Years }\end{array}$ & $\begin{array}{l}30-44 \\
\text { Years }\end{array}$ & $\begin{array}{l}45-60 \\
\text { Years }\end{array}$ & Total & $\begin{array}{c}P \\
\text { value }\end{array}$ \\
\hline Malignant Serous & 0 & 2 & 0 & 1 & 3 & 0.001 \\
\hline Malignant Mucinous & 0 & 1 & 2 & 0 & 3 & 0.001 \\
\hline Malignant Endometroid & 0 & 1 & 1 & 0 & 2 & 0.001 \\
\hline Malignant Clear Cell & 0 & 0 & 1 & 0 & 1 & 0.001 \\
\hline Malignant Granulosa Stromal Cell Tumor & 0 & 0 & 0 & 2 & 2 & 0.001 \\
\hline Dysgerminoma & 1 & 3 & 0 & 0 & 4 & 0.001 \\
\hline Endodermal Sinus Tumor & 1 & 0 & 0 & 0 & 1 & 0.001 \\
\hline $\begin{array}{l}\text { Malignant mixed forms of germ cell } \\
\text { tumor }\end{array}$ & 2 & 0 & 0 & 0 & 2 & 0.001 \\
\hline Malignant mixed sex cord tumor & 0 & 1 & 0 & 0 & 1 & 0.001 \\
\hline Total & 4 & 8 & 4 & 3 & 19 & 0.001 \\
\hline
\end{tabular}

Comparison between histological type and age groups $<30$ years and $\geq 30$ years, using chi-square test.

the $0-15$ age group $(6 / 8-75 \%)$ while epithelial tumors were found to be more common in all other age groups. Sex cord stromal tumors were the rarest group of tumors in all age groups.

Similarly in the $0-15$ age group teratoma (2/8) and mixed forms of germ cell tumor $(2 / 8)$ were more frequent than other types while serous was the most common tumor histological type in all other age groups.

19 malignant tumors were found out of 95 cases. The most common malignant type of tumor was Dysgerminoma (4/19) followed my serous and mucinous malignant tumors $(3 / 19$ each). There is a significant association of ovarian tumors in age less than 30 years as compared to older ages, $\mathrm{p}$ value $<0.05$ (Table 4).

\section{Discussion}

According to the results of our research, $78.9 \%$ of the tumors studied were benign, $1.1 \%$ were borderline and $20 \%$ were malignant. These percentages coincide with studies conducted in other parts of the world, such as Saudi Arabia, ${ }^{12}$ in which $72.8 \%$ of all ovarian neoplasms were benign and $22 \%$ are malignant, India, ${ }^{17}$ where $75.2 \%$ of ovarian tumors were benign, and Nepal, ${ }^{4}$ where $83.9 \%$ were benign. This is also similar to data collected from western countries ${ }^{18}$ where 75.0
$80.0 \%$ of ovarian tumors were found to be benign. However, a similar study conducted in Pakistan in Aga Khan University Hospital, Karachi, ${ }^{13}$ showed that $40.81 \%$ of ovarian tumors were malignant and $59.18 \%$ were benign. A study in Peshawar ${ }^{14}$ showed a much lower percentage $(10.29 \%)$ of malignant lesions. Another research in Peshawar ${ }^{15}$ had similar results. There were discrepancies observed between the rates of malignant neoplasms reported in these studies. These maybe due to the different sample sizes and different sampling techniques used.

The age range of the participants in our study was between 3 and 65 years and the mean age of diagnosis was found to be 29.58 years \pm 11.493 . The maximum incidence of ovarian tumors was in the age group $15-$ 30. This is consistent with the findings of a study in India ${ }^{8}$ where the maximum incidence of ovarian masses was determined to be between 21 to 40 years of age, as well as a study in Nepal. ${ }^{4}$ A similar age incidence is also reported in other studies by V Nayak, ${ }^{19}$ Swamy $\mathrm{GG}^{11}$ and by Bhattacharya MM et al. ${ }^{21}$ These results however differ from the pattern seen in Western Countries ${ }^{18}$ where peak incidence is between 50 and 70 years. It is probable that dietary and lifestyle differences, exposure to environmental pollutants and carcinogens account for this variation between the developing and developed world. More exploration is 
needed to evaluate the risk factors that might cause an earlier age of presentation of ovarian tumors in the developing world.

In the $0-14$ age group, 4 out of the $8(50 \%)$ tumors studied were malignant. Similarly, in the $45-60$ age group, 3 out of the $6(50 \%)$ tumors were found to be malignant. In our study, therefore, these two age groups constituted the groups with the highest rates of malignancy. Saeed $\mathrm{M}^{3}$ reported similar findings in his study; in which all of the 8 ovarian tumors (100\%) found in the age group of $10-16$ years were found to be malignant.

In our study, $72.6 \%$ of ovarian tumors were of epithelial origin, $23.2 \%$ were derived from germ cell and $4.2 \%$ were sex cord stromal tumors. These findings are very similar to the research conducted in Ayub Medical College (76.5\% epithelial tumors) ${ }^{14}$ and also comparable to other studies where the percentage of surface epithelial type of ovarian tumors were $65.71 \%$, $63.50 \%, 62.36 \%$ respectively. ${ }^{8,13,19}$ The proportion of germ cell tumors in our study was similar to that seen in a research by $\mathrm{Z}$ Ahmed (27. 13\%), ${ }^{13} \mathrm{~L}$ Abdullah $(28 \%)^{12}$ and Mondal SK $(23.1 \%){ }^{5}$ However, it is higher than that seen in studies carried out in Rawalpindi $^{20}(19 \%)$ and Bangalore ${ }^{19}(13.97 \%)$ and significantly lower than the percentage of germ cell tumors of a study in Nepal $(42.2 \%)$. ${ }^{4}$ This can be attributed to the sample size of our study but could also possible be the result of various ecological, genetic and socioeconomic factors.

Serous tumors constituted the most common histological subtype in our study (49.5\%). These included both benign (serous cystadenoma) and malignant (serous cystadenocarcinoma) lesions. This percentage is comparable to the proportion of serous tumors found in studies in $\operatorname{India}^{8}(42.8 \%)$ and Lahore ${ }^{3}(42.5 \%)$ while it is higher than the percentage found in other researches in $\operatorname{Karachi}^{13}$ (31.1\%), Rawalpindi ${ }^{20}$ (36.5\%), Saudi Arabia $^{12}$ (39.7\%) and $\mathrm{Nepal}^{4,10}$ (34.1\% and 36\% respectively). The second most common histological subtype was mucinous $(16.8 \%)$, closely followed by teratomas $(15.8 \%)$. This pattern is consistent with studies in other parts of the world ${ }^{12,10}$ as well as Pakistan..$^{13,20}$ However one study in Nepal by $\mathrm{Jha}^{4}$ discovered that mature cystic teratoma was the most common neoplastic lesion.

In the $0-14$ age group, germ cell tumors were found to be more common with $75 \%$ of the cases being of germ cell origin. This is consistent with a study conducted on peripubertal ovarian tumors in Lahore by Saeed $\mathrm{M}^{3}$ where $87.5 \%$ of tumors were found to be germ cell tumors and in Nepal ${ }^{10}$ where 8 out of the $12(66.7 \%)$ neoplastic lesions in patients below 20 years of age were of germ cell origin. The results in a study in Saudi Arabia, ${ }^{12}$ however, show different results with only $39 \%$ of tumors in the $0-19$ age group arising from germ cell and epithelial tumors being the dominant type of tumor. In our study, epithelial tumors were found to be more common in all other age groups while sex cord stromal tumors had the lowest frequency in all age groups. These findings align with the results by Mondal SK $^{5}$ where surface epithelial tumors were the most common above the age of 16 years. The same pattern appears in numerous other studies. ${ }^{12,4,10}$

Looking at the age distribution of ovarian lesions, we find that serous lesions were the most common in all age groups except the $0-14$ years where teratomas were found to be more frequent. Teratomas were also reported to be the most common lesion by Ahmad $\mathrm{Z}$ in this age group. ${ }^{13}$

Out of the 19 malignant tumors in our study, we saw that dysgerminoma was the most common $(21 \%)$ lesion overall, followed by serous and mucinous malignant tumors (15.7\% each). Similar results were reported by Maharjan et al. ${ }^{10}$ This, however, contrasts with the findings in Karachi by Ahmad Z, ${ }^{13}$ where out of the 349 malignant ovarian neoplasms, serous cystadenocarcinoma (29.5\%) was most common, followed by mucinous cystadenocarcinoma $(15.7 \%)$ and dysgerminoma made up only $6.5 \%$ of the malignant lesions, being the third most common lesion. A study in Peshawar by Yasmin $S^{14}$ also showed different results with granulosa cell tumors and endometriod carcinoma being the most common malignant lesion ( 2 out of 7 cases each) and dysgerminoma accounting for 1 case out of the 7 malignant tumors studied. These regional differences can be attributed to varying sample sizes but it is likely that local environmental factors also play a role. Dysgerminoma was also the most frequent malignant lesion in all the age groups except for the $0-15$ age group in which malignant mixed form of germ cell tumor was found to be more common. Thus, from our study, we see that the histological pattern of benign and malignant lesions in the $0-15$ age group does not conform to the trend seen in the other age groups which potentially means that the behavior of ovarian lesions in younger females is unique and deserves further detailed study. 


\section{Conclusion}

According to our study, ovarian tumors were common between the ages of 15 to 29 years. Benign neoplastic lesions were more common than malignant neoplastic lesions. Among the histological types of neoplastic lesions, surface epithelial tumors were the leading type, followed by germ cell tumors. The commonest benign tumor was serous cystadenoma and the most common malignant tumor was dysgerminoma. The highest rates of malignancy were in the $0-14$ and $45-60$ age groups. There is a significant association of ovarian tumors in age less than 30 years as compared to older age groups.

\section{Acknowledgments}

We would like to express our gratitude to Department of Pathology King Edward Medical University and Dr. Fariha Salman from the Department of Community Medicine KEMU for her guidance and analysis during completion of this research project.

\section{References}

1. Stricker TP, Kumar V,Neoplasia. In: Kumar V, Abbas AK, Fausto N, Aster JC, Editors. Robbins and Cotran Pathologic Basis of Disease. 8th ed. New Delhi: Saunders Elsevier, 2010: 260-266.

2. Ambreen A, Anwar K, Hussain A. Maternal and Fetal Outcome of Pregnancies Complicated by Ovarian Tumor. J Annals of KEMU, 2010; 6 (1): 5.

3. Saeed M, Rana T. This is High Time to Look into Peripubertal Ovarian Tumors. J Annals of KEMU, 2010; 16 (3): 215-219.

4. Jha R, Karki S. Histological pattern of ovarian tumours and their age distribution. Nepal Med Coll J. 2008; 10 (2): 81-8.

5. Banyopadhyay R, Mondal SK, Mondal PK, Nag DR, Roychowdhury S, Sinha SK. Histologic pattern, bilaterality and clinical evaluation of 957 ovarian neoplasms: A 10 - year study in a tertiary hospital of eastern India. J Can Res Ther. 2011; 7 (4): 433-437.

6. Quirk JT, Natarajan N. Ovarian cancer incidence in the United States, 1992-1999. Gynaecol Oncol. 2005; 97
(2): 519-523.

7. Modi D, Rathod GB, Delwadia KN, Goswami HM. Histopathological pattern of neoplastic ovarian lesions. IAIM. 2016; 3 (1): 51-57.

8. Makwana HH, Maru AM, Lakum NR, Agnihotri AS, Trivedi NJ, Joshi JR. Relative Frequency and Histopathological Pattern of Ovarian Masses. Int J Med Sci Public Health, 2014; 3 (1): 81-84.

9. Sharma I, Sharma U, Dutta UC. Pathology of ovarian tumour-A hospital based study. Valley Int J. 2014; 1 (6): 284-286.

10. Maharjan S. Clinicomorphological Study of Ovarian Lesions. JCMC. 2013; 3 (6): 17-24.

11. Swamy GG, Satyanarayana N. Clinicopathological analysis of ovarian tumors-A study on five years samples. Nepal Med Coll J. 2010; 12 (4): 221-223.

12. Abdullah LS, Bondagji NS. Histopathological pattern of ovarian neoplasms and their age distribution in the western region of Saudi Arabia. Saudi Med J. 2012; 33 (1): 61-65.

13. Ahmad Z, Kayani N, Hasan SH, Muzaffar S, Gill MS. Histological Pattern of Ovarian Neoplasma. J Pak Med Assoc. 2000; 97 (12).

14. Yasmin S, Yasmin A, Asif M. Clinicohistological pattern of ovarian tumours in Peshawar region. J Ayub Med Coll Abbottabad, 2008; 20 (4): 11-13.

15. Khan MM, Sharif N, Ahmad S. Morphological Spectrum of Mature Ovarian Teratoma. Gomal J Med Sci. 2014; 12 (9): 76-80.

16. World Health Organization. Histological Typing of Ovarian Tumors. Geneva: World Health Organization, 1973.

17. Pilli GS, Suneeta KP, Dhaded AV, Yenni VV. Ovarian tumours: a study of 282 cases. J Indian Med Assoc. 2002; 100: 420, 423-424, 447.

18. Aria M, Utsunomiya, Miki Y. Familial breast and ovarian cancers. Int J Clin Oncol. 2004; 9: 270-282.

19. Nayak V, Sreelatha S, Vani BR, Shobarani S. Clinicopathological Study of Ovarian Tumours. Journal of Evolution of Medical and Dental Sciences, 2014; 3 (53): 12230-12233.

20. Iqbal J, Aurangzaib, Naseem A, Shahid A. Pattern of Ovarian Pathologies. J Rawal Med Coll. 2013; 17 (1): 113-115.

21. Bhattacharya MM, Shinde SD, Purandare VN. A clinicopathological analysis of 270 ovarian tumours. J Postgrad Med. 1980; 26: 103. 